July 2009

\title{
Symptomatic Cerebral Vasospasm after Surgical Ligation of Unruptured Aneurysms
}

James Harrop MD

Thomas Jefferson University

Robert H. Rosenwasser MD

Thomas Jefferson University

Follow this and additional works at: https://jdc.jefferson.edu/jhnj

\section{Let us know how access to this document benefits you}

\section{Recommended Citation}

Harrop, James MD and Rosenwasser MD, Robert H. (2009) "Symptomatic Cerebral Vasospasm after Surgical Ligation of Unruptured Aneurysms," JHN Journal: Vol. 4 : Iss. 3 , Article 7.

DOI: https://doi.org/10.29046/JHNJ.004.3.007

Available at: https://jdc.jefferson.edu/jhnj/vol4/iss3/7

This Article is brought to you for free and open access by the Jefferson Digital Commons. The Jefferson Digital Commons is a service of Thomas Jefferson University's Center for Teaching and Learning (CTL). The Commons is a showcase for Jefferson books and journals, peer-reviewed scholarly publications, unique historical collections from the University archives, and teaching tools. The Jefferson Digital Commons allows researchers and interested readers anywhere in the world to learn about and keep up to date with Jefferson scholarship. This article has been accepted for inclusion in JHN Journal by an authorized administrator of the Jefferson Digital Commons. For more information, please contact: JeffersonDigitalCommons@jefferson.edu. 


\section{Symptomatic Cerebral Vasospasm after Surgical Ligation of Unruptured Aneurysms}

\author{
James S. Harrop, MD, FACS ${ }^{1,3}$, William Mitchell, MD', Rocco Armonda, MD', \\ Jeffrey Thomas, MD', Robert H. Rosenwasser, MD, FACS, FAHA ${ }^{2,4}$ \\ ${ }^{1}$ Resident (1999), Department of Neurosurgery, Thomas Jefferson University Hospital \\ ${ }^{2}$ Professor (1999), Department of Neurosurgery, Thomas Jefferson University \\ ${ }^{3}$ Associate Professor (2009), Department of Neurosurgery, Thomas Jefferson University \\ ${ }^{4}$ FACS, FAHA, Professor and Chair (2009), Department of Neurosurgery, Thomas Jefferson \\ University (2009)
}

This is an unpublished paper from 2000. The main author was Dr. Harrop, then a resident and now a faculty member. Readers interested in current knowledge in the area should visit www.pubmed.gov and search the medical subject heading terms "Intracranial aneurysm," and "vasospasm, intracranial."

\section{Abstract}

\section{Background}

Cerebral artery vasospasm accounts for the majority of delayed neurological deficits in ruptured aneurysm patients. We report two cases and review the literature of patients who developed symptomatic vasospasm after treatment for unruptured cerebral artery aneurysms with clip ligation. Pre- and post-operative imaging and studies revealed absence of subarachnoid or focal hemorrhage.

\section{Case Description}

In a series of 104 consecutive cerebral artery aneurysm patients that underwent uncomplicated ligation without intra-operative rupture, two patients developed delayed neurologic deficits due to severe cerebral vasospasm. Both patients had no stigmata of rupture and were treated electively. Post-operative transcranial dopplers and angiography facilitated the early recognition of vasospasm. Permanent neurologic injury was prevented with the use of hypertensive, hemodilution and hyperdynamic $(\mathrm{HHH})$ therapy along with endovascular treatment, intra-arterial papaverine and angioplasty.

\section{Conclusion}

After uncomplicated treatment of unruptured intracranial aneurysms, the cerebral vasculature may proceed to severe vasospasm by an unrecognized mechanism. This can be reversed with institution of $\mathrm{HHH}$ and endovascular therapy.

\section{Introduction}

The major morbidity in patients who survive the initial hemorrhage or rupture from an intracranial aneurysm is cerebral vasospasm. The degree and severity of vasospasm typically correlates with the amount of subarachnoid hemorrhage. ${ }^{1}$ However, cerebral vasospasm before and after microsurgical treatment of unruptured aneurysms is sparsely reported in the literature* We report two additional cases, review the existing literature, and illustrate successful treatment with $\mathrm{HHH}$ and endovascular therapy.

\section{Case Histories}

\section{Case I}

A 38-year-old female was diagnosed with an incidental left internal carotid artery (ICA) bifurcation aneurysm following a minor motor vehicle accident (Figure 1). Three months after diagnosis she underwent an uncomplicated elective craniotomy and clip ligation of the aneurysm. At the time of surgery, there was no sign of previous hemorrhage or local vessel spasm. The patient was discharged home neurologically intact on post-operative day POD 5. She was readmitted due to a sudden onset of expressive aphasia and right-handed hemiparesis on POD 7 (Figure 2). Anticonvulsive levels were

circa 1999
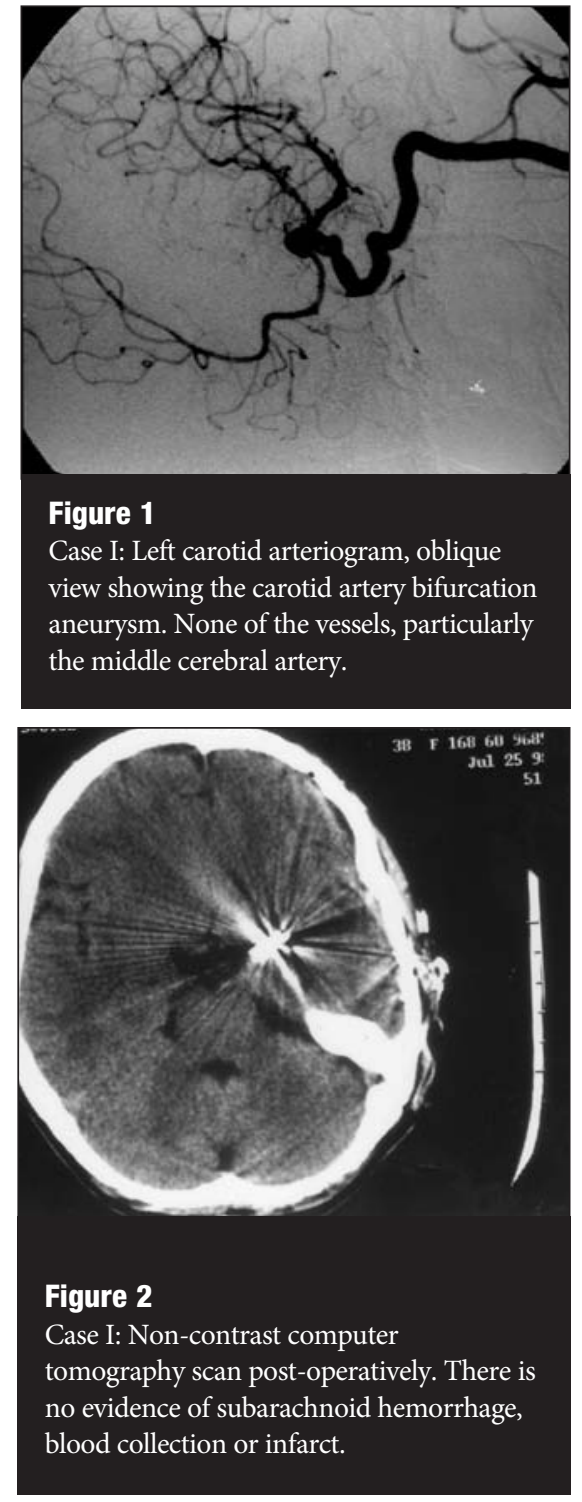

therapeutic and an EEG was unremarkable. On POD 10, due to transient episodes of aphasia and hemiparesis during her repeat hospitalization, an arteriogram was performed that showed severe vasospasm of the left MCA and ACA (Figure 3). HHH therapy was begun and her aphasia and hemiparesis resolved. Despite maximal medical therapy the patient continued to experience episodes of aphasia 

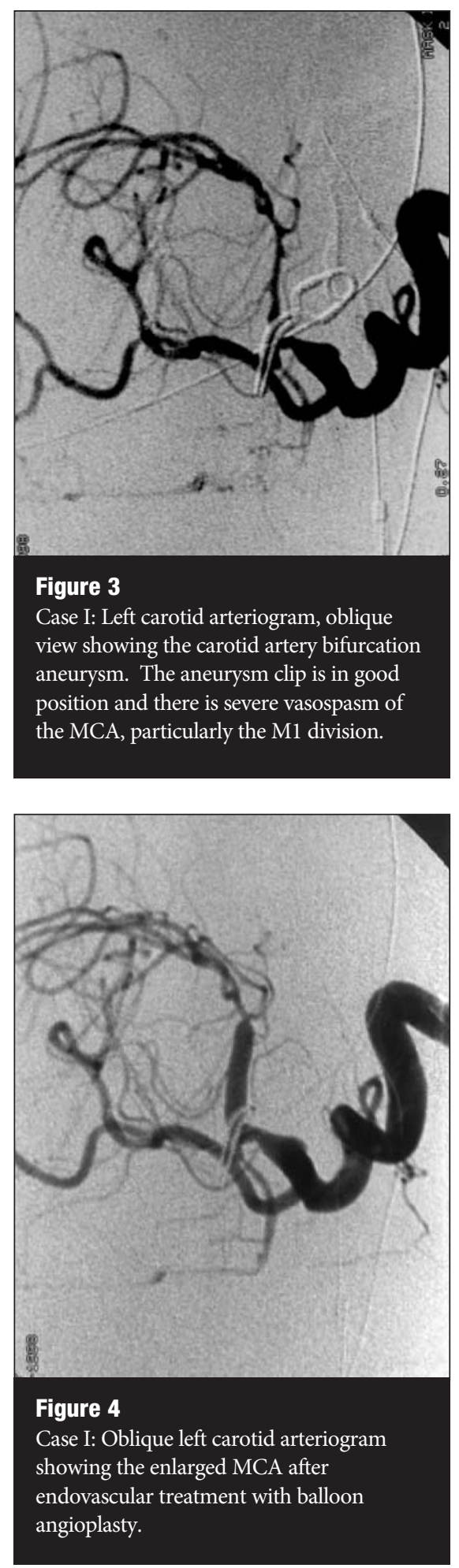

and hemiparesis. On POD 18 she therefore underwent cerebral angioplasty and dilatation

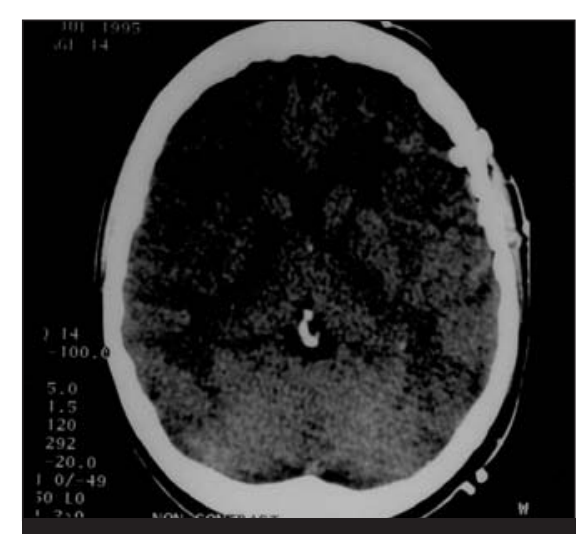

\section{Figure 5}

Case II: Post-operative noncontrast CT scan after clip ligation of the middle

cerebral artery aneurysm. There is no subarachnoid or focal hemorrhage, and infarction is absent.

of the left middle cerebral vessel (Figure 4). At her three-month follow-up, she remains neurologically intact.

\section{Case II}

A 39-year-old female with chronic migraines had a MRI of the head and was diagnosed with incidental mirror middle cerebral artery (MCA) aneurysms that were confirmed by cerebral arteriogram. She had no history of sudden onset of headaches, nuchal rigidity, photophobia or suggestion of subarachnoid hemorrhage; imaging and CSF examination showed no evidence of hemorrhage. The patient underwent uneventful clip ligation of her left MCA aneurysm. There was no intraoperative hemorrhage, and the arachnoid showed no signs of previous hemorrhage. POD 1 the patient developed a mild expressive aphasia. A computer tomography scan revealed minimal left hemispheric edema with no evidence of infarction or hemorrhage (Figure 5). Post operatively, cranial dopplers (TCD) were significantly elevated, and treatment with $\mathrm{HHH}$ therapy returned her to her neurologic baseline. HHH therapy includes hemodilution, hypervolemic, and pressor-induced hypertensive therapy to maximize cerebral blood flow. An arteriogram was performed after further increases in TCD showed severe left supraclinoid, middle and anterior cerebral artery vasospasm (Figure 6). After three separate treatments of intra-arterial papaverine and angioplasty, in addition to medical therapy, the cerebral vasospasm resolved on POD 17. At three-month follow-up she had a nonfocal neurologic exam and was able to function independently at her previous level of employment.

\section{DISCUSSION}

There are only twelve ${ }^{\dagger}$ reported cases in the literature of symptomatic vasospasm after uncomplicated treatment of unruptured aneurysms, including the present two cases. ${ }^{2-9}$ These cases illustrate that this vasospasm can be reversed with aggressive medical and endovascular treatment. A retrospective analysis of 104 Hunt/Hess Grade 0 patients' radiographs, medical records, and clinical follow-ups were compared to historical controls.

In 1975, Simeone and Peerless first reported three cases of an intracranial aneurysm without subarachnoid hemorrhage that in the acute postoperative period after uncomplicated clip ligation progressed to severe cerebral vasospasm. ${ }^{9}$ These patients manifested with sudden onset of new neurologic deficits, which upon evaluation with angiogram was secondary to severe cerebral artery vasoconstriction. Two of these patients maintained permanent neurologic deficits as a result of this ischemic interval. ${ }^{9}$ All 12 of these cases in the literature had either history not consistent with ruptured aneurysm, or negative spinal fluid analysis in the setting of minor headache. The mean patient age was 37.5 years (25-54), the majority of patients were female (11/12), and all aneurysms were located in the anterior circulation. In five of the patients, the cerebral vasospasm was noted prior to surgery and this subset of patients consisted entirely of females with posterior communicating artery aneurysms..$^{3-5,7,8}$

Patients whose vasospasm developed during the postoperative period had a mean occurrence of 4.4 days (1-9), and interval of symptomatic spasm between 12-17 days. All patients had craniotomy and clipping ligation of their aneurysms except one of Simeone's patients who underwent craniotomy and copper coil embolization. No patients were treated with $\mathrm{HHH}$ therapy prior to the two cases presented in this paper. Bloomfield did use volume expansion and steroids to treat one patient and noted a neurologic improvement and only a mild deficit on follow-up. ${ }^{2}$

The pathogenesis of cerebral vasospasm is poorly understood. In patients that have subarachnoid hemorrhage, there is a direct correlation between the amount of subarachnoid blood and the incidence of vasospasm. ${ }^{1}$ This correlation of subarachnoid blood and vasospasm is 


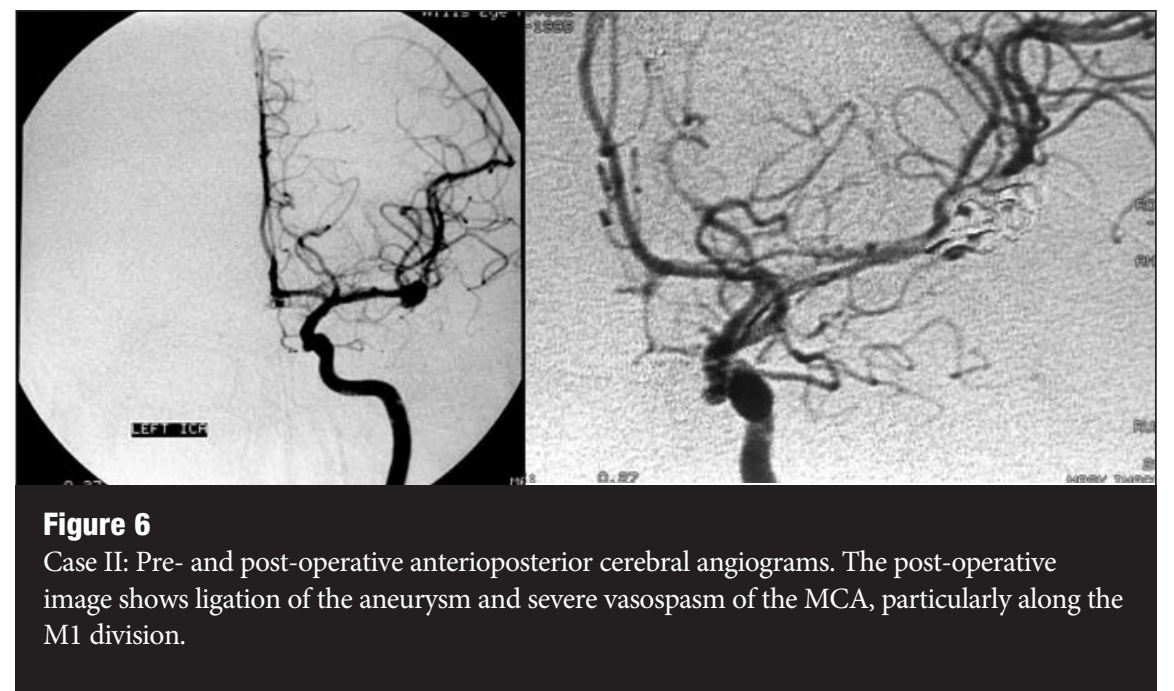

supported by the data that irrigation of the subarachnoid cisterns in humans and primate models decreases the incidence of vasospasm. ${ }^{10}$ However, subarachnoid blood alone is not an absolute predictor for cerebral vasospasm. Therefore, other influences must be present for cerebral vasospasm to occur and produce cerebral ischemia.

The factors that initiate the pathogenesis of vasospasm may vary from individual genetic make-up and reactivity on a cellular level to the influences of external stimuli. It is not uncommon to see localized spasm of the arterial vessels from direct manipulation either in the form of surgical retraction or intra-arterial manipulation during radiology or endovascular surgery. Hyper-reactivity of cerebral vessels is not only present in patients who suffer subarachnoid aneurismal hemorrhages. Cranial trauma is the single most common cause of subarachnoid hemorrhage, however only $5-10 \%$ of these patients experience cerebral vasospasm. ${ }^{11}$ Symptomatic vasospasm has also been documented to occur during the presence of meningitis, injections of toxins (panopaque), and after craniotomy and basal tumor resections. ${ }^{10,12,13}$

Uncomplicated clip ligation of cerebral aneurysm can progress to severe vasospasm, which maybe an infrequent occurrence favoring female patients. In our patients it was lifethreatening and medically intractable requiring endovascular intervention. The present cases are the first documented cases of unruptured cerebral aneurysms that proceeded to severe vasospasm, and which were successfully treated with $\mathrm{HHH}$ and endovascular therapy. Cerebral vasospasm should enter into the differential of any grade 0 patient who develops postoperative neurologic deficits, since it is readily reversible with current treatment regimens. In this series there was approximately a two percent $(2 / 104)$ incidence of symptomatic cerebral vasospasm which illustrates this may be a more prevalent disease process than was previously believed.

\section{References}

1. Fisher, C.M., J.P. Kistler, and J.M. Davis, Relation of cerebral vasospasm to subarachnoid hemorrhage visualized by computerized tomographic scanning. Neurosurgery, 1980. 6(1): p. 1-9.

2. Bloomfield, S.M. and V.K. Sonntag, Delayed cerebral vasospasm after uncomplicated operation on an unruptured aneurysm: case report. Neurosurgery, 1985. 17(5): p. 792-6.

3. Clarke, C.E., et al., Thunderclap headache. Lancet, 1988. 2(8611): p. 625 .

4. Day, J.W. and N.H. Raskin, Thunderclap headache: symptom of unruptured cerebral aneurysm. Lancet, 1986 2(8518): p. 1247-8.

5. Dinning, T.A., Timing of surgery for leaking cerebral aneurysms: clinical, radiological and radio-isotopic considerations. Proc Aust Assoc Neurol, 1973. 9: p. 219-26.

6. Fein, J.M., Unruptured aneurysms and cerebral vasospasm, in Cerebral Arterial Spasm, R.H. Wilkins, Editor. 1980, Williams and Wilkins: Baltimore. p. 499-504.

. Friedman, P., H.H. Gass, and M. Magidson, Vasospasm with an unruptured and unoperated aneurysm. Surg Neurol, 1983. 19(1): p. 21-5.

8. Raynor, R.B. and H.D. Messer, Severe vasospasm with an unruptured aneurysm: case report. Neurosurgery, 1980. 6(1): p. 92-5

9. Simeone, F.A. and S.J. Peerless, Prolonged cerebral vasospasm without subarachnoid hemorrhage, in Subarachnoid Hemorrhage and Cerebrovascular Spasm, R.R. Smith and J.T. Robertson, Editors. 1975, Charles C Thomas: Springfield, Illinois. p. 206-223.

10. Mizukami, M., et al., Prevention of vasospasm by early operation with removal of subarachnoid blood. Neurosurgery, 1982. 10(3): p. 301-7.

11. Suwanwela, C. and N. Suwanwela, Intracranial arterial narrowing and spasm in acute head injury. J Neurosurg, 1972. 36(3): p. 314-23.

12. Smith, R.A., H.F. Collier, and F.O. Underwood, Cerebral vasospasm following myelography. Surg Neurol, 1973. 1(2): p. $87-90$.

13. Wilkins, R.H., Intracranial arterial spasm after procedures other than operations for intracranial aneurysm, in Cerebral Arterial Spasm, R.H. Wilkins, Editor. 1980, Williams and Wilkins: Baltimore. p. 505-509.

\title{
Brain power
}

\author{
Jefferson. \\ Hospital for Neuroscience
}

1-800-JEFF-NOW

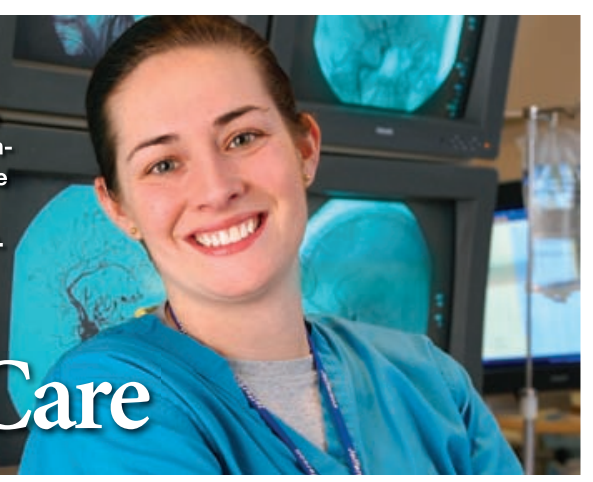

